\title{
Organizational and methodological aspects of distance learning for children with special educational needs
}

\author{
A.A. Guseynova ${ }^{1 *}$, and $V . V$. Manuilova ${ }^{2}$ \\ ${ }^{1}$ Moscow City University, Moscow, Russia \\ ${ }^{2}$ Moscow City University, Moscow, Russia
}

\begin{abstract}
The article considers organizational and methodological aspects of distance learning for children with disabilities, taking into account their special educational needs. The results of a survey of support specialists on the use of distance learning in educational organizations are presented.
\end{abstract}

\section{A problem statement}

Currently, the concept of modernization of Russian education states the principle of equal access of students with special educational needs to a full-fledged quality education in accordance with their interests and inclinations, regardless of the material wealth of the family, place of residence and health status. One of the ways to implement this requirement is to organize distance education for people with various developmental disabilities $[1,2]$.

\subsection{The objective of the work}

Content analysis of literature sources on the problem of organizing distance education for individuals of various nosological groups has shown that there are technical difficulties in organizing this form of training, such as incompatibility of general and special technical tools, as well as specific difficulties that are caused by the type of violation and the corresponding characteristics of the student. To solve these problems, we conducted a special research and developed organizational and methodological aspects of distance education for children with special educational needs [3, 4].

\section{Materials and the results of the research}

To determine the degree of use of distance education in working with children with special educational needs in educational institutions, we developed a questionnaire for support specialists, in which respondents were required to note the numbers of responses corresponding to their opinion $[5,6]$. They could complete the answers in the "other" items. The questionnaire included the following questions:

*Corresponding author: ipcs-profped@yandex.ru 
* What categories of children with disabilities (CWD) are enrolled in your educational organization?

1.hearing impaired 2. vision impaired 3. speech impaired 4. musculoskeletal disorders 5. mental retardation 6 . intellectual disability 7. autism spectrum disorders 8 . severe (multiple) disorders 9. somatic diseases

* The number of students in your group or class:

1.Total__ 2. of them with disabilities

* Age of children with disabilities you work with

1.preschool 2. Junior school 3. other

* Your experience of using distance education to work with children with special educational needs

1.don't have 2. less than 1 year 3 . from 1 to 3 years 4 . more than 3 years

* The scope of distance learning in your practice:

1.working with children; 2 . working with colleagues; 3 . working with parents.

* How often do you use distance learning in correctional and pedagogical work

1.once a week; 2 . once a month 3 . every day; 4 . I can't answer

* What difficulties do you face in the course of distance learning for people with disabilities?

* Do you think that the use of distance education increases the effectiveness of pedagogical work in working with students with disabilities:

1.Yes; 2. no; 3. I can't answer.

* Would you like to improve their skills in the field of distance learning?

1.Yes. 2.no. 3.I can't answer

* Does the administration of the educational organization encourage the use of distance education?

1.Yes. 2.no. 3.I can't answer

* Please provide some information about yourself:

* Your education: 1. secondary pedagogical 2. secondary special (defectological) 3 . higher pedagogical 4. higher special (defectological) 5. other (write)

* Your age: 1 . up to 25 years 2. from 25 to 30 years 3. from 30 to 40 years 4 . from 40 to 50 years 5 . from 50 to 60 years 6 . over 60 years

* Work experience with children with OOP 1 . up to 3 years 2 . from 3 to 5 years 3 . from 5 to 10 years 4 . from 10 to 15 years 5 . from 15 to 25 years 6 . 25 years or more

45 support specialists - speech therapists, psychologists, and speech pathologists-took part in the survey. According to the results of the survey, the study participants noted that the educational organization is visited by students with various developmental disorders, according to conclusion of the psychological, medical and pedagogical Commission, such as speech disorders (47\%), musculoskeletal disorders (33\%), vision (53\%), hearing (20\%), mental retardation $(40 \%)$, autism spectrum disorders $(27 \%)$. The results are shown in figure 1. 


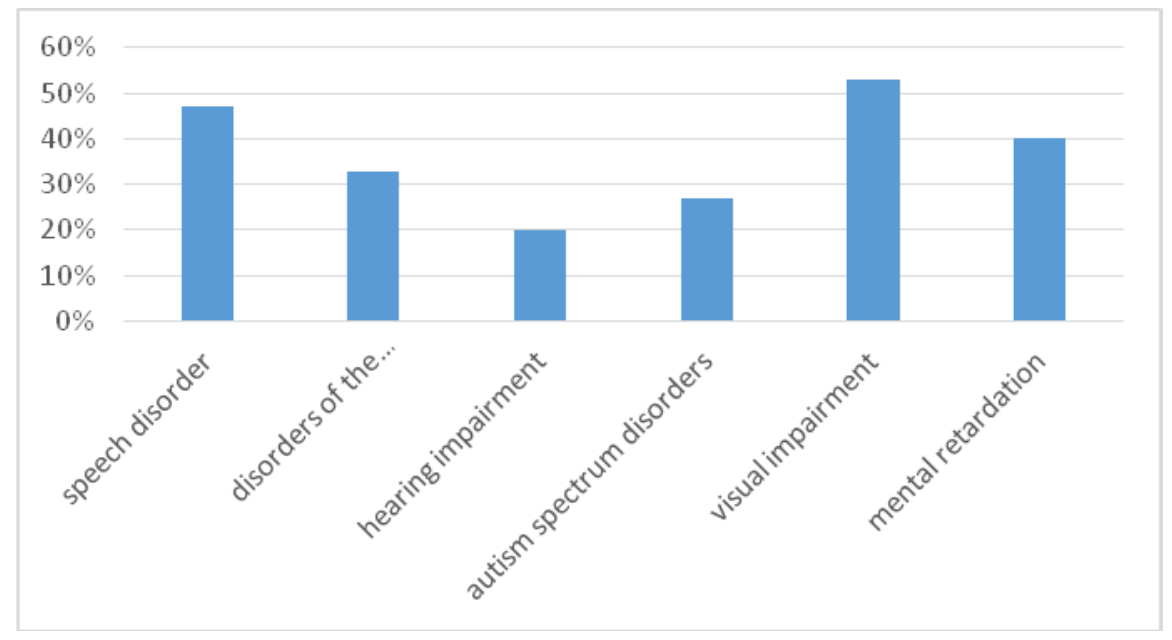

Fig. 1. Contingent of children with special educational needs.

The results of the survey also showed that the distance education is not fully used in the educational process with students with various developmental disabilities. Only $40 \%$ of respondents have experience using this form for more than three years, only $27 \%$ of participants use it for less than three years, $13 \%$ noted that they use it for less than one year, and, unfortunately, $20 \%$ of respondents noted that they do not yet have experience using remote technologies, and also believe that it is not advisable to use this form in the educational process with children with special educational needs. The results are shown in figure 2 .

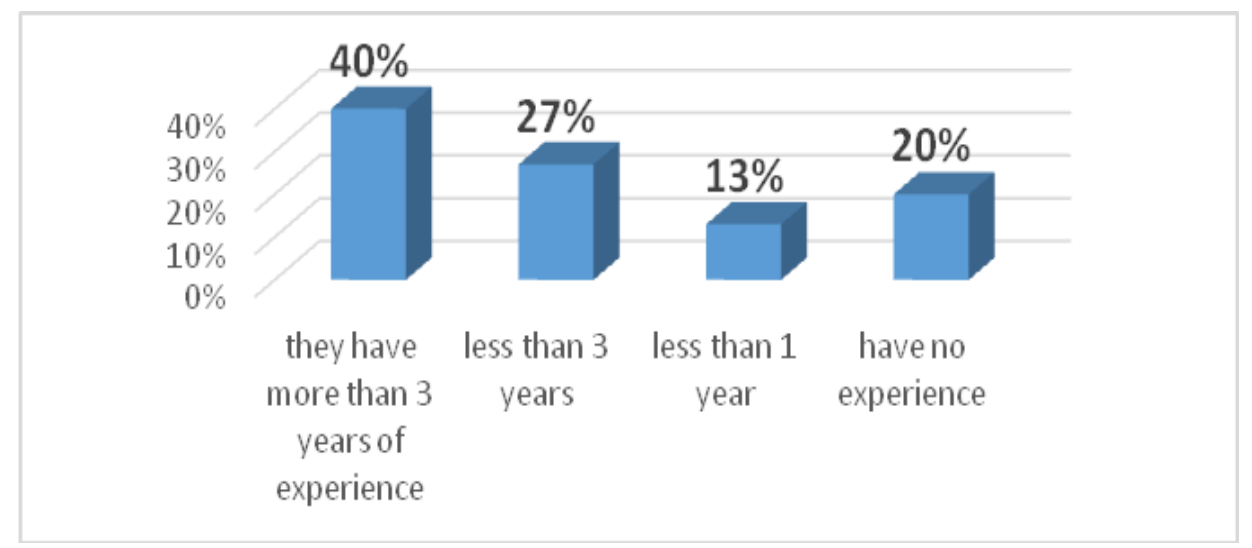

Fig. 2. Experience of using distance education in correctional and pedagogical work with students with OOP.

Regarding the question "scope of distance education in your practice» the majority of respondents $(67 \%)$ noted that when conducting correctional and pedagogical classes, the rest $(33 \%)$ emphasized during interaction with parents of children with developmental disabilities. Among the survey participants were respondents who stressed that they do not use distance education in their professional activities due to the insufficient equipment of the educational organization with information technology tools.

As for the frequency of using distance education in correctional and pedagogical work, the majority of participants $(47 \%)$ noted that they use it once a week mostly, once a month $27 \%$ of respondents, every day only $20 \%$, and the remaining $6 \%$ found it difficult to answer 
this question. The results are shown in figure 3.

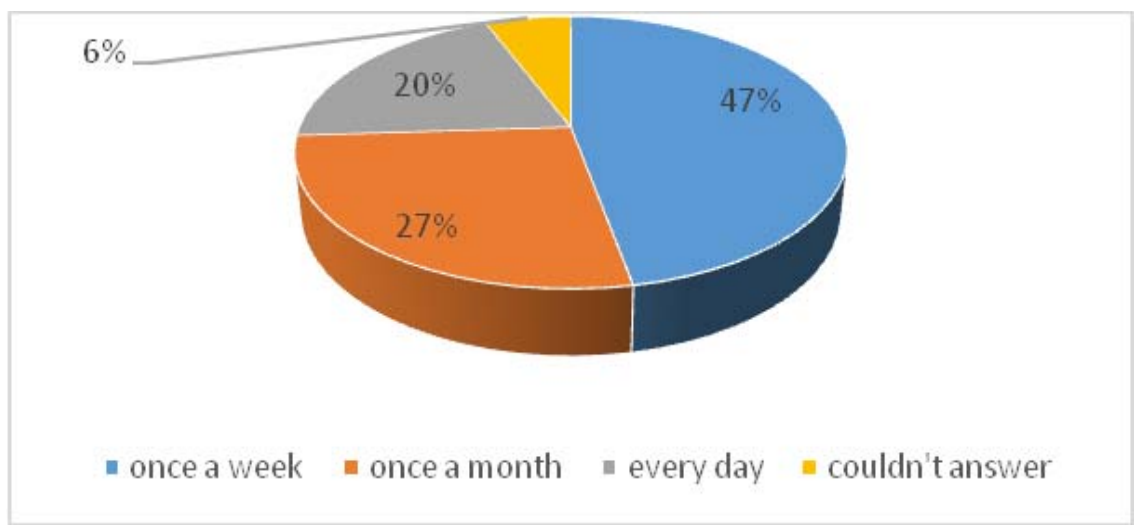

Fig. 3. Frequency of using distance education in working with children with OOP.

The majority of the study participants $(87 \%)$ believe that the use of distance education in working with students with various developmental disabilities makes it possible to diversify the conduct of correctional classes, as well as increases motivation and interest in the educational process.

To the question of the questionnaire «would You like to improve your skills in the field of distance education» the majority of respondents (67\%) said "Yes", while the remaining $33 \%$ found it difficult to answer.

To the questionnaire question: «Does the administration of an educational organization encourage the use of distance learning? " the majority of participants (87\%) responded positively.

Noting information about their educational level, the study participants noted that $73 \%$ of respondents have higher special (defectological) education, 20\% have higher pedagogical education, but have completed professional retraining courses and work as support specialists, $7 \%$ have secondary professional special education.

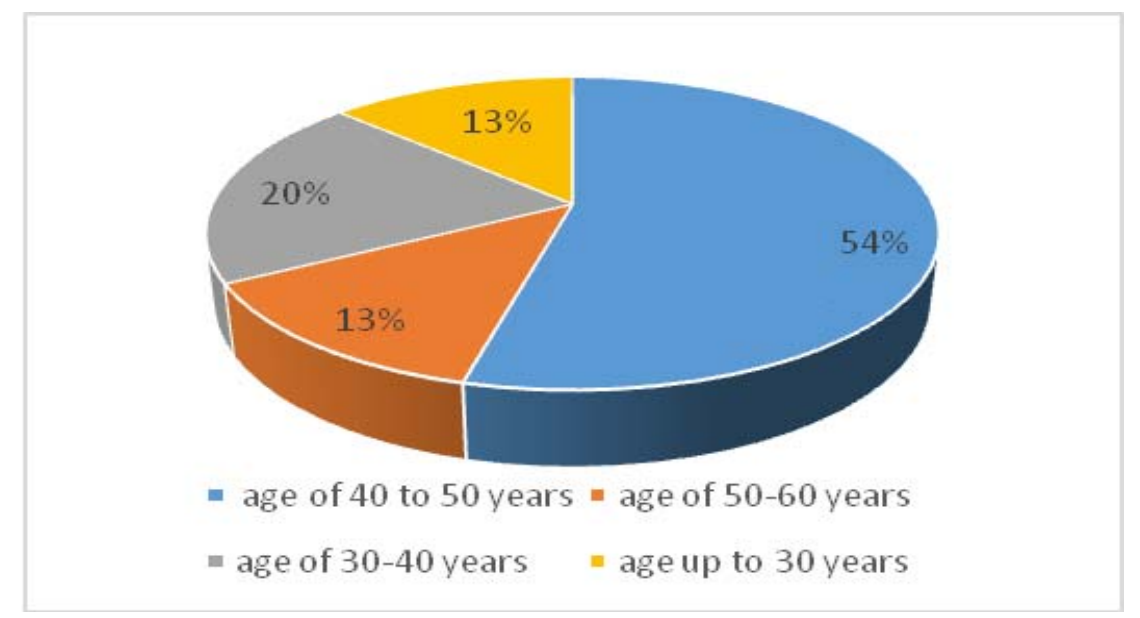

Fig. 4. Age of participants research.

The majority of participants of the experiment (54\%) have more than 25 years of teaching experience with students with developmental disabilities, $13 \%$ from 15 to 25 years, and $27 \%$ have 3 to 5 years of work experience. 


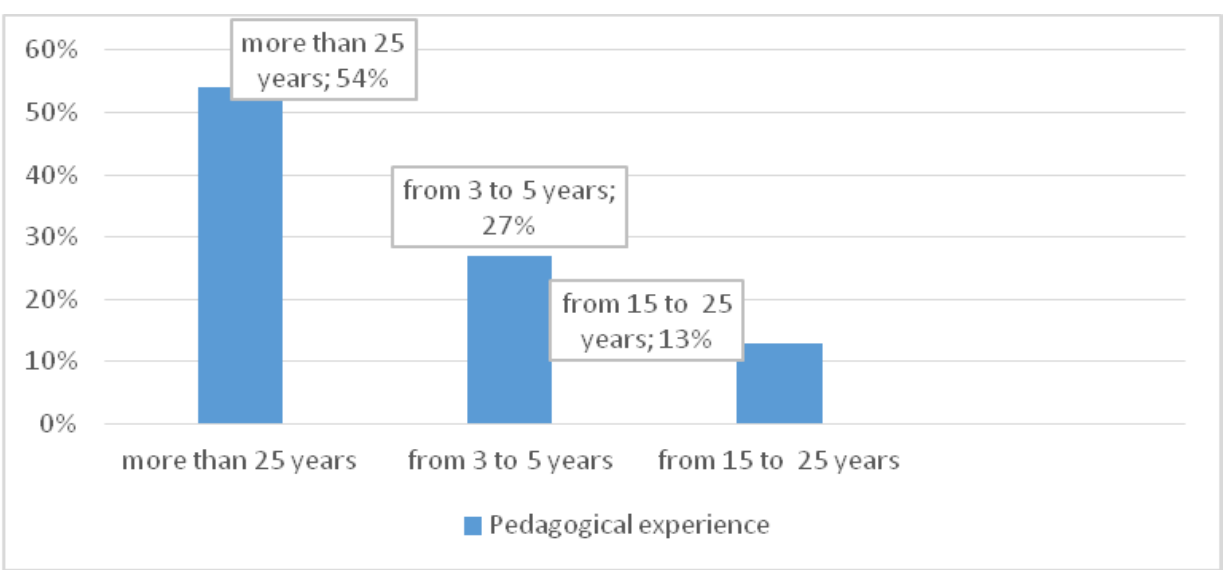

Fig. 5. Work experience of the experiment participants.

Based on the results of the survey, we identified a list of conditions that must be met when organizing and conducting distance learning for individuals of this category, namely:

- take into account the special educational needs of students with disabilities;

- organize the workplace taking into account the broken functions;

- to regulate training activities tailored to the individual recommendations;

- follow the exercise regime in accordance with individual recommendations of doctors;

- dose the time spent working on your computer, tablet, and other gadgets;

- perform regular changes of activities in order to prevent fatigue;

- to shorten the lesson by using a computer;

- perform motor warm-UPS and special relaxation exercises in the classroom.

During distance learning for children with special educational needs, it is very important to pay attention to the student's posture, since many children with developmental disabilities cannot hold the sitting position independently or sit incorrectly and uncomfortably $[7,8]$. It is necessary to ensure the most comfortable position during training. It is important to ensure: the ability to maintain balance; prevent sliding from the chair; the ability to work freely with your hands; control the position of the head, etc. To do this, it is recommended to use orthopedic devices: special chairs, verticals that allow you to fix the student in the desired position. It is necessary that the furniture meets the needs of students with special educational needs (height-adjustable tables and chairs, single desks with a recess for a wheelchair, etc.) $[9,10]$.

The special organization of the educational process and special equipment of the student's workplace are also of great importance. The workplace should not only provide a comfortable and convenient position of the student in space, but also comply with medical recommendations $[11,12]$.

Depending on the goals of educational activities, it is recommended to use special auxiliary technical means. The main consumers of special technical equipment are children with disorders of the musculoskeletal system. Among children with motor disorders, this equipment is most often used by students with cerebral palsy, namely children with spastic diplegia and hyperkinetic forms of the disease.

For those students who, due to severe motor or sensory disorders, cannot work on a computer using a standard set of technical means (a normal keyboard and a mouse), it is recommended to use special technical means that compensate for impaired functions [13].

To facilitate the use of distance learning by persons with developmental disabilities, the use of special keyboards is recommended. Different types of keyboards are adapted to 
certain types of restrictions. For students who have visual impairments in addition to motor disorders, it is recommended to use a black keyboard for the visually impaired, with standard-sized keys with white letters in an enlarged format. The size of the keyboard for visually impaired people is larger than the standard one, and the symbols on the buttons are large and embossed. Keyboards for the right and left hands are also developed.

It is also recommended to use a virtual (on-screen) keyboard during distance learning for children with developmental disabilities who cannot use standard and special keyboards. For students with limited hand mobility (for example, for users with muscular dystrophy), a membrane keyboard is created — an electronic keyboard without separate mechanical moving parts, made in the form of a flat, usually flexible, surface with a key pattern applied to it. The keyboard supports the following functions:

- adjustable key press delay (keyboard response speed);

- double-tap elimination function (if you hold your finger on the same key, you will not press again, to press the next key, you need to remove your finger from the keyboard);

- adjusting the speed of repeated pressing and blocking the modifying key, such as SHIFT, Ctrl, etc. (for example, you can type a capital letter with one hand, and you can also press keys that require simultaneous pressing on a standard keyboard - CTRL-ALT-delete);

- full replacement of mouse functions (the cursor moves with the keys on the keyboard, as well as mouse clicks) $[14,15]$.

We recommend using a lightweight keyboard that contains a reduced number of buttons for quick access to applications in working with students with intellectual disabilities. The buttons are provided with clear non-verbal icons.

Distance education for visually impaired people also uses Braille keyboards and printers, as well as voice programs that allow you to enter and read texts from the screen.

For students with speech disorders, databases of graphic images have been developed that facilitate communication, programs that allow them to guess the words they started and complete them [16].

In addition to the special keyboard, it is recommended to use special mice that replace the standard mouse during distance learning. There are various types of special mice joysticks, trackballs, keyboards, foot-operated, for head. Keyboard mice have eight keys that control the movement of the cursor in different directions and function keys like on a mouse-joystick or roller. Mouse joysticks are recommended for use with children with severe motor disorders. By controlling the mouse keys, you can reduce the cursor movement speed as much as possible, enable one of the special movement functions: "horizontal only", "vertical only», etc. Mouse roller have the same functions as the mousejoystick. In distance education for children who find it difficult to control a special mouse with their hands, it is recommended to use head mice. Expressed hyperkinesis does not allow you to fix the cursor on the object even for a short period of time required for implementation.

Synchronous and asynchronous distance education technologies are also highlighted. When using synchronous (on-line) communication tools, the teacher and the student interact at the same time. This form is more similar to the traditional one, especially if participants in the learning process are visualized (for example, Skype is used). The advantage of synchronous distance learning over asynchronous learning is that the social deprivation of the student is less pronounced when using synchronous tools than when using asynchronous tools.

In addition, in Russia it is not always possible to use a synchronous form due to time differences in different time zones, since this form of distance education requires simultaneous involvement of all participants in the educational process. In addition, there are software tools that translate spoken speech into written speech (titles), which allows people with hearing impairments to be involved in this process. It is also possible to 
transmit information in the sign language of the deaf. However, as in all other cases, it is necessary to take into account the features and specific needs of people with hearing impairments (for example, the need to acquire lip-reading skills, develop auditory perception, auditory self-control, etc.) and carefully approach the choice of forms of training (traditional, distance, mixed) [17].

The asynchronous (off-line) method of interaction between the teacher and the student provides students with the opportunity to determine the time of classes themselves. In this form, you can access the training material repeatedly, at an individual pace; the speed of perception and processing of information does not matter; you can ask questions by phone (orally) or by e-mail (in writing). This type of technology includes email, mailing lists, teleconferencing, and others. E - mail- practically does not require any special skills, a cheap and fast method of transmitting information that does not depend on the time of transmission and the location of the recipient, allows the use of additional auxiliary technologies, provides for the use of written language only. Email distribution service - a copy of the email is automatically sent to all subscribers. The main form of speech is written.

In the course of distance education for children with special educational needs, special attention should be paid to the teacher's speech. The teacher's speech should be clear and legible, with emphasized articulation, without a sharp increase in voice and with more repetitions than in a normal lesson $[18,19]$.

When evaluating the current and final results of distance education, it is necessary to provide each student with the opportunity to demonstrate them in accordance with their individual characteristics due to the type of violation. This can be a preliminary review of the certification plan, providing additional time for the response, replacing the oral form of tasks with a written one or Vice versa, varying the means and forms of presenting the response, using special technical devices, and so on. The methods of accessing information should be the same as they were during the training. At the same time, standards and evaluation criteria must be met [20].

\section{Conclusions}

Thus, the effectiveness of using distance education is determined by the creation of such necessary conditions for its implementation as the availability and accessibility of appropriate technologies, technical support and consulting of support specialists, professional development of teaching staff in the field of the development and application of new didactic tools, etc.

\section{References}

1. Education Act in the Russian Federation", (N 273-FZ, December 29, 2012)

2. I.V. Evtushenko, A.P. Simonov, I.L. Solovyeva , L.R. Khuzina, K.A. Armeninova, R.Z. Zakirov, A.I. Evtushenko, G.Y. Eroshina, T.L. Lyubimova, S.A. Osokina, Modern high technologies, 7, 157-163 (2019)

3. V.V. Narushevich, On the need to introduce distance education among children with disabilities and young people with disabilities in Saint Petersburg, Higher education for disabled people: proceedings of the international scientific and practical conference, 34-36 (Saint Petersburg, 2000) 
4. Yu.S. Avraamov, The practice of forming an information and educational environment based on remote technologies, Telecommunications and Informatization of education., 2, 40-42 (2004)

5. I.V. Evtushenko, M.V. Zhigoreva, I.Yu. Levchenko, I.A. Nikolskaya, I.M. Novikova, V.V Tkacheva, T.N. Volkovskaya, Distance education: teacher about schoolchildren with disabilities, p. 456 (2013)

6. I.Yu. Levchenko, O.G Prikhodko, A.A Guseynova, V.V Manuilova, Inclusive education: special conditions for inclusion of students with disabilities in the educational space (2018)

7. A.A. Andreev, Didactic foundations of distance education (2001)

8. M.S. Meleshkina, Distance education technologies for people with disabilities as a socializing factor, Scientific and methodological electronic journal "Concept", 95-99 (2017)

9. N.S. Myasnikov, Innovations in education: distance learning for children with limited health opportunities, Topical issues of modern pedagogy: materials of the IV international conference (Ufa: Summer, 2013)

10. E.I. Leonhard, Normalizing the conditions of upbringing and training of children with disabilities in inclusive education, Methodological guide, p. 278 (Moscow, 2018)

11. A.A. Guseynova, Special conditions for obtaining education for students with severe (multiple) developmental disorders. In the collection: problems of implementing the Federal state educational standard for children with disabilities, Collection of articles based on the materials of the round table, 47-54 (GBOU VPO MGPU, Moscow, 2016)

12. O.I. Kukushkina, Information technologies in special education: conceptual ideas and their practical implementation (2013)

13. O.G. Prikhodko, The system of early comprehensive differentiated rehabilitation and developmental assist for children with cerebral palsy (GBOU VPO MGPU, Moscow, 2009)

14. V.V. Manuylova, Humanitarian sciences, 2 (38), 23-30 (2017)

15. O.V. Yugova, Variable strategies for early psychological and pedagogical assist for children with developmental disabilities and their family (GBOU VPO MGPU, Moscow, 2012)

16. K.E. Shchukina, Information technologies in teaching schoolchildren with disabilities (Information and communication technologies in the modern educational process: scientific publication, Collection of scientific articles, 284-292 (Chelyabinsk: publishing house, 2016)

17. B.V. Belyavsky, I.L. Solovieva, Special Education, 2 (42), 5-14 (2016)

18. V.I. Ovsyannikov, Main stages of development of distance learning and its theoretical support (2001)

19. N.V. Bondarenko, Formation of lifelong education in Russia: analysis based on the results of all-Russian polls of the country's adult population (Moscow: National Research University Higher School of Economics, 2017)

20. I.N. Popova, I.L. Solovieva, Education and training of children with developmental disabilities, 2, 42-48 (2020) 